\title{
Surgical Excision For Para-Aortic Lymph Node Metastases After Radical Colorectal Cancer Resection: Case Series of Six Patients
}

Hiroka Kondo ( $\nabla$ kondo.hiroka@twmu.ac.jp )

Tokyo Women's Medical University https://orcid.org/0000-0003-1416-4383

\section{Yasumitsu Hirano}

Saitama Medical University International Medical Center

\section{Shigeki Yamaguchi}

Tokyo Women's Medical University

\section{Research Article}

Keywords: colorectal cancer, para-aortic lymph node metastases, recurrence

Posted Date: May 6th, 2021

DOl: https://doi.org/10.21203/rs.3.rs-473712/v1

License: (c) (1) This work is licensed under a Creative Commons Attribution 4.0 International License.

Read Full License 


\section{Abstract}

Background: The reported frequency of colorectal cancer (CRC) metastasis to para-aortic lymph nodes (PLNs) varies but is quite low (approximately 1 to $4 \%$ ), impeding present attempts at large-scale trials. In particular, there are few reports of PLN recurrences after radical resection of CRC. We report 6 cases of PLN dissection for PLN recurrence after radical CRC surgery.

Case presentation: Six patients underwent surgery at our hospital between April 2007 and December 2018 for recurrence of PLN metastasis after radical resection of CRC. At preoperative imaging, 2 patients had lymph node metastases cephalad to the renal vein. One of them had complete R0 resection; the other had biopsy only, because R0 resection was not possible. Complete resection was performed in all 4 patients who had enlarged PLNs only caudal to the renal vein, and the 4 survivors who were confirmed during the observation period are the 4 patients who had PLN metastases caudad to the renal vein.

Conclusions: Surgical removal of PLN metastases in the aftermath of CRC resection may improve the prognosis in those patients with isolated metastases caudad to the renal vein.

\section{Background}

Upon diagnosis, colorectal cancer (CRC) is associated with distant metastasis in approximately 10 to $20 \%$ of cases [1]. If feasible, excision is recommended for liver or lung metastasis, anticipating a 5-year overall survival rate of 30 to 50 percent [2] [3] [4]. Recent chemotherapeutic advances have prolonged survival to nearly 2 years in patients with unresectable tumors and distant metastases [5], although the prognosis after treatment with chemotherapy alone remains poor.

Because para-aortic lymph nodes (PLNs) are extraregional with respect to CRC, metastases are considered distant spread, signaling stage IV disease, and usually warranting chemotherapy as the principal treatment. Surgical excision of PLNs may be of long-term benefit in some cases, but criteria for such interventions have yet to be clearly delineated. According to Nakai et al, 5-year survival after radical $\mathrm{CRC}$ resection improves significantly after radical dissection of PLN metastases [6]. Some authors are thus recommending an aggressive surgical approach, especially for solitary or metachronous PLN metastases without other distant spread [7] [8].

The reported frequency of CRC metastasis to PLNs varies, but is quite low (approximately 1 to 4\%) [9], impeding present attempts at large-scale trials. In particular, there are few reports of PLN recurrences after radical resection of CRC. We report 6 cases of PLN dissection for PLN recurrence after radical CRC surgery.

\section{Case Presentation}

Six patients underwent resection at our hospital between April 2007 and December 2018 for recurrence of PLN metastasis after radical resection of CRC. We retrospectively examined short-term postoperative 
data, focusing on operation time, blood loss, laparoscopic surgery rate, range of PLN dissection, tumor histology, and postoperative complications and hospitalization, and analyzed recurrence-free and overall survival. PLN metastases were determined by preoperative abdominopelvic computed tomography (CT) marked by a minor axis greater than $10 \mathrm{~mm}$, irregular margins, and uneven contrast enhancement.

Table 1 shows the initial patient background and surgical results. There were 2 men and 4 women, with an average age of 66 (42 to 79) years. Five patients had left-sided colon cancer or rectal cancer, and only one had right colon cancer. Laparoscopic resection was the first procedure in 4 cases. In all cases, the histological type was moderately differentiated tubular adenocarcinoma. All CRC resections were R0 (margin negative). One patient (patient 2) had intraoperative peritoneal dissemination, which was resected at the same time. Three of 4 patients with stage 3 disease received postoperative adjuvant chemotherapy. Patient 2 was also scheduled for adjuvant chemotherapy following stage 4 R0 resection, but was unable to proceed due to cerebral hemorrhage.

The preoperative diagnostic and short-term postoperative results after dissection of PLN recurrences are summarized in Table 2. In 2 of the 6 patients (patient 3 and patient 5), preoperative diagnostic imaging revealed metastases cephalad to the renal vein (Fig. 1). Patient 3, who initially had stage I (T1NOMO) disease, also had right cervical lymphadenopathy, which confounded confirmation of the CRC recurrence. PLN involvement was beaded at time of surgery, thus preventing curative resection and resulting in biopsy alone. In the other 5 patients, PLNs with suspected metastases were completely excised. The median survival in these 5 patients was 1926 days. Long-term outcomes are shown in Table 3. Ultimately, 4 of the 6 patients survived during an average observation period of 5 years. In all 4 survivors, PLN metastases were caudad to renal vein. A representative CT scan from this group (patient 1 ) is shown in Fig. 2. Two of the 4 survivors experienced later recurrences (at approximately 1 year), one displaying peritoneal dissemination and the other lung metastasis with peritoneal dissemination.

\section{Discussion And Conclusions}

Excision of simultaneous or metachronous CRC metastasis to liver or lung has conferred long-term survival benefit in carefully selected patients [2] [3] [4] [10] [11], and at one point in the past (1959), PLN dissection was proposed as an adjunct to resection of rectal cancer [12]. However, subsequent survival rates failed to improve, and there were concerns over rising postoperative complication rates. Thus, PLN dissection it is not a part of current mainstay therapeutics, and chemotherapy has instead become the chief mode of treatment for PLN metastasis. Nevertheless, there are some reported cases of prognostic improvement through PLN removal [13], implying that it may be a worthwhile strategy once the surgical criteria are clarified.

The appropriate extent of lymph node dissection is critical and remains uncertain under these circumstances. At our hospital, PLN dissection is reserved for patients whose preoperative assessments indicate a potential for cure, limiting surgery to removal of enlarged lymph nodes. Although all of our patients routinely underwent open surgery, the safety of laparoscopic excision of PLNs has been 
documented elsewhere [14]. In this series, the sole postoperative complication was a Clavien-Dindo grade I paralytic ileus, underscoring the safety of these interventions. There were no later PLN recurrences in any of the 6 patients. Although the number of cases examined was quite small, it seems that surgical removal of tumor-bearing nodes is acceptable as a treatment of choice.

There have been various indications that the number of PLN metastases affects patient prognosis [15] [16]. Choi et al have indicated an excisional limit of two PLN metastases for improved prognosis [17], and Yamada et al have discouraged excisions in patients with three or more PLN metastases, given the low recurrence-free survival rate [18]. In the present study, 5 of 6 patients had solitary PLN metastases (one patient with three), and there were five $\mathrm{R} 0$ resections. The patient with three metastases had a pulmonary recurrence and peritoneal dissemination at approximately one year after surgery, but both lesions were resected, further extending survival for more than 5 years. In 2 of 6 patients, nodal metastasis occurred cephalad to the renal vein. Radical resection was impossible in one, who received biopsy only for diagnosis; the other relapsed 7.5 months after nodal excision and died 2 years later. These outcomes suggest that excision should be discouraged if PLN metastases are found cephalad to the renal vein.

The guideline from the National Comprehensive Cancer Network maintains that metachronous liver metastases are less disseminated and thus carry a better prognosis than synchronous liver metastases [19]. The same may hold true for PLN metastases, and we have shown herein that overall nodal involvement and the scope of surgery are not absolute determinants.

Our findings suggest that surgical removal of PLN metastases in the aftermath of CRC resection may improve the prognosis in those patients with isolated metastases caudad to the renal vein.

\section{Abbreviations}

CRC: colorectal cancer

PLNs: para-aortic lymph nodes

CT: computed tomography

\section{Declarations}

Ethics approval and consent to participate

All study participants granted informed consent. The study design was approved by the Ethics Committee of Saitama Medical University International Medical Center (Number: 20-074), and all procedures were conducted in accordance with the Helsinki Declaration of 1996.

Consent for publication: All patients consented to the release of personal medical data for research and publication purposes. 
Availability of data and materials: All data generated or analyzed during this study are included in this published article.

Competing interests: The authors declare that they have no competing interests.

Funding: No funding sources contributed to this effort.

Author contributions: $\mathrm{HK}$ and $\mathrm{YH}$ analyzed and interpreted the patient data. HK drafted this manuscript under supervision of $\mathrm{YH}$ and SY. All authors have read and approved the final document.

Acknowledgments: The authors wish to thank experts at BioMed Proofreading LLC for English copyediting.

\section{References}

1. Watanabe T, Muro K, Ajioka Y, Hashiguchi Y, Ito Y, Saito Y, Hamaguchi T, Ishida H, Ishiguro M, Ishihara S, et al: Japanese Society for Cancer of the Colon and Rectum (JSCCR) guidelines 2016 for the treatment of colorectal cancer.Int J Clin Oncol 2018, 23:1-34.

2. Nordlinger B, Sorbye H, Glimelius B, Poston GJ, Schlag PM, Rougier P, Bechstein WO, Primrose JN, Walpole ET, Finch-Jones M, et al: Perioperative chemotherapy with FOLFOX4 and surgery versus surgery alone for resectable liver metastases from colorectal cancer (EORTC Intergroup trial 40983): a randomised controlled trial.Lancet 2008, 371:1007-1016.

3. Nordlinger B, Sorbye H, Glimelius B, Poston GJ, Schlag PM, Rougier P, Bechstein WO, Primrose JN, Walpole ET, Finch-Jones $\mathrm{M}$, et al: Perioperative FOLFOX4 chemotherapy and surgery versus surgery alone for resectable liver metastases from colorectal cancer (EORTC 40983): long-term results of a randomised, controlled, phase 3 trial.Lancet Oncol 2013, 14:1208-1215.

4. Pfannschmidt J, Dienemann $\mathrm{H}$, Hoffmann $\mathrm{H}$ : Surgical resection of pulmonary metastases from colorectal cancer: a systematic review of published series.Ann Thorac Surg 2007, 84:324-338.

5. Hochster HS, Hart LL, Ramanathan RK, Childs BH, Hainsworth JD, Cohn AL, Wong L, Fehrenbacher L, Abubakr Y, Saif MW, et al: Safety and efficacy of oxaliplatin and fluoropyrimidine regimens with or without bevacizumab as first-line treatment of metastatic colorectal cancer: results of the TREE Study.J Clin Oncol 2008, 26:3523-3529.

6. Nakai N, Yamaguchi T, Kinugasa Y, Shiomi A, Kagawa H, Yamakawa Y, Numata M, Furutani A: Longterm outcomes after resection of para-aortic lymph node metastasis from left-sided colon and rectal cancer.Int J Colorectal Dis 2017, 32:999-1007.

7. Min BS, Kim NK, Sohn SK, Cho CH, Lee KY, Baik SH: Isolated paraaortic lymph-node recurrence after the curative resection of colorectal carcinoma.J Surg Oncol 2008, 97:136-140.

8. Bae SU, Hur H, Min BS, Baik SH, Lee KY, Kim NK: Which Patients with Isolated Para-aortic Lymph Node Metastasis Will Truly Benefit from Extended Lymph Node Dissection for Colon Cancer? Cancer Res Treat 2018, 50:712-719. 
9. Gagniere J, Dupre A, Chabaud S, Peyrat P, Meeus P, Rivoire M: Retroperitoneal nodal metastases from colorectal cancer: Curable metastases with radical retroperitoneal lymphadenectomy in selected patients.Eur J Surg Oncol 2015, 41:731-737.

10. Shah SA, Haddad R, Al-Sukhni W, Kim RD, Greig PD, Grant DR, Taylor BR, Langer B, Gallinger S, Wei $\mathrm{AC}$ : Surgical resection of hepatic and pulmonary metastases from colorectal carcinoma.J Am Coll Surg 2006, 202:468-475.

11. Mise Y, Imamura H, Hashimoto T, Seyama Y, Aoki T, Hasegawa K, Beck Y, Sugawara Y, Makuuchi M, Nakajima J, Kokudo N: Cohort study of the survival benefit of resection for recurrent hepatic and/or pulmonary metastases after primary hepatectomy for colorectal metastases.Ann Surg 2010, 251:902-909.

12. Stearns MW, Jr., Deddish MR: Five-year results of abdominopelvic lymph node dissection for carcinoma of the rectum.Dis Colon Rectum 1959, 2:169-172.

13. Shibata D, Paty PB, Guillem JG, Wong WD, Cohen AM: Surgical management of isolated retroperitoneal recurrences of colorectal carcinoma.Dis Colon Rectum 2002, 45:795-801.

14. Yamamoto S, Kanai T, Yo K, Hongo K, Takano K, Tsutsui M, Nakanishi R, Yoshikawa Y, Nakagawa M: Laparoscopic para-aortic lymphadenectomy for colorectal cancer with clinically suspected lymph node metastasis.Asian J Endosc Surg 2019, 12:417-422.

15. Song SH, Park SY, Park JS, Kim HJ, Yang CS, Choi GS: Laparoscopic para-aortic lymph node dissection for patients with primary colorectal cancer and clinically suspected para-aortic lymph nodes.Ann Surg Treat Res 2016, 90:29-35.

16. Ogura A, Akiyoshi T, Takatsu Y, Nagata J, Nagasaki T, Konishi T, Fujimoto Y, Nagayama S, Fukunaga $\mathrm{Y}$, Ueno M: The significance of extended lymphadenectomy for colorectal cancer with isolated synchronous extraregional lymph node metastasis.Asian J Surg 2017, 40:254-261.

17. Choi PW, Kim HC, Kim AY, Jung SH, Yu CS, Kim JC: Extensive lymphadenectomy in colorectal cancer with isolated para-aortic lymph node metastasis below the level of renal vessels.J Surg Oncol 2010, 101:66-71.

18. Yamada K, Tsukamoto S, Ochiai H, Shida D, Kanemitsu Y: Improving Selection for Resection of Synchronous Para-Aortic Lymph Node Metastases in Colorectal Cancer.Dig Surg 2019, 36:369-375.

19. Benson AB, 3rd, Venook AP, Cederquist L, Chan E, Chen YJ, Cooper HS, Deming D, Engstrom PF, Enzinger PC, Fichera A, et al: Colon Cancer, Version 1.2017, NCCN Clinical Practice Guidelines in Oncology.J Natl Compr Canc Netw 2017, 15:370-398.

\section{Tables}

Due to technical limitations, table $1,2 \& 3$ is only available as a download in the Supplemental Files section.

\section{Figures}




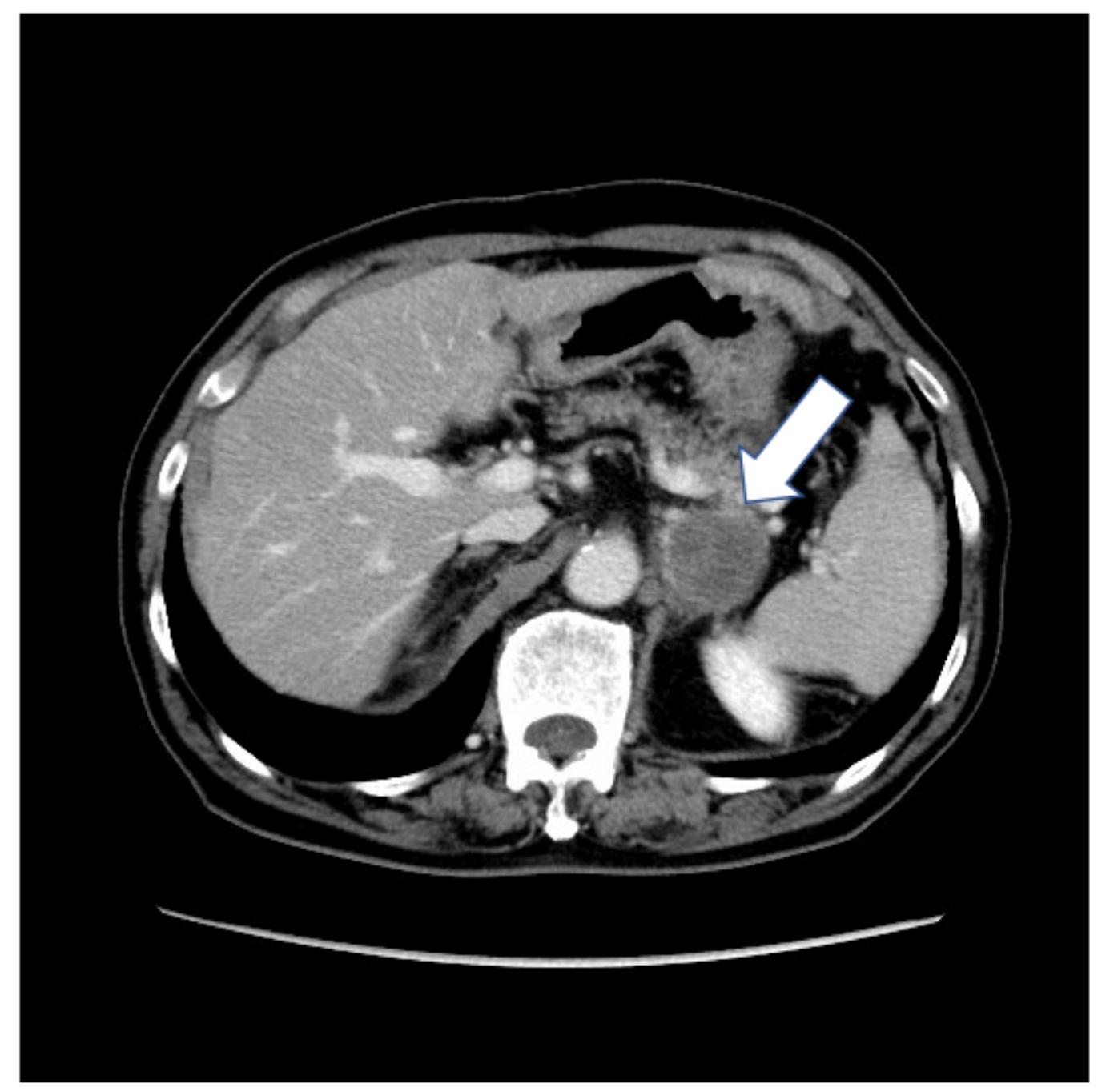

Figure 1

CT image of patient 5. PLN that is swollen cephalad to the renal vein is observed. (arrow) 


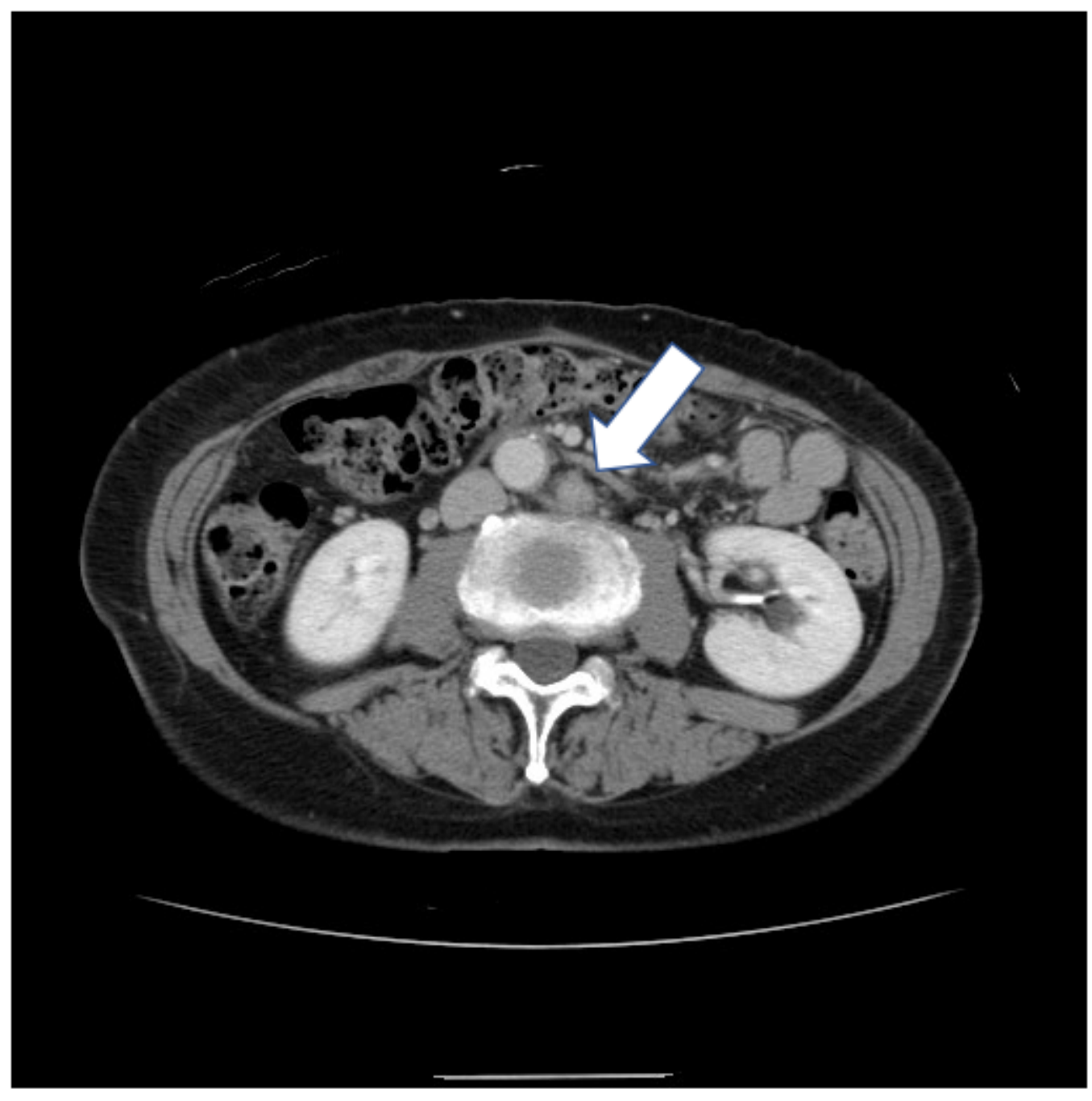

Figure 2

CT image of patient 1. PLN metastases were caudad to renal vein. (arrow)

\section{Supplementary Files}

This is a list of supplementary files associated with this preprint. Click to download.

- tables.xlsx 